\title{
PROTOTYPE APLIKASI MOBILE PRESERVASI WARISAN BUDAYA INDONESIA BERBASIS CROWDSOURCING
}

\author{
I Ketut Resika Arthana1, Gede Aditra Pradnyana², I Made Ardwi Pradnyana ${ }^{3}$ \\ 1,2,3 Department of Informatics Technology Education \\ Faculty of Engineering and Vocational \\ Universitas Pendidikan Ganesha, Singaraja Indonesia \\ resika@undiksha.ac.id, gede.aditra@undiksha.ac.id, ardwi.pradnyana@undiksha.ac.id
}

\begin{abstract}
Abstrak
Setiap daerah memiliki ciri khas budaya masing-masing seperti rumah adat, bahasa, pakaian, peralatan, bangunan, karya seni dan lain sebagainya. Setiap budaya memiliki filosofi yang bisa digunakan sebagai panutan hidup. Oleh karena itu, sangat penting untuk mendokumentasikan dan menyebarkan informasi budaya secara luas sehingga generasi muda memiliki pengetahuan terhadap budaya di Indonesia. Tantangan besarnya adalah bagaimana mengumpulkan dan mendokumentasi informasi budaya serta mengemasnya dalam bentuk menarik sehingga masyarakat lebih mudah dan tertarik untuk mempelajari budaya Indonesia. Perkembangan teknologi internet dan perangkat mobile yang sangat pesat. Penetrasi internet dan perangkat mobile sangat tinggi di masyarakat. Sebagian besar masyarakat memiliki perangkat mobile dan internet. Keberadaan teknologi tersebut bisa dimanfaatkan untuk mendukung dokumentasi dan penyebaran informasi budaya Indonesia. Teknologi pendukung seperti LBS(Location Based Service) bisa dimanfaatkan untuk menentukan lokasi objek budaya yang ada. Tantangan utama dalam pengembangan sistem preservasi budaya ini adalah sumber dan kualitas konten. Untuk menghadapi tantangan tersebut, maka diterapkan konsep crowdsourcing untuk menyumbangkan dan menilai kualitas konten. Disamping dari masyarakat luas, potensi sumber konten budaya juga dari mahasiswa yang mengembangkan konten pembelajaran sebagai tugas akhir/ kerja praktik. Untuk itu maka pada penelitian ini dikembangkan aplikasi mobile untuk preservasi warisan budaya di Indonesia yang disebut dengan aplikasi WADAYA. Tahapan penelitian ini menggunakan ADDIE (Analyze, Design, Developmet, Implementation dan Evalution). Tahap Analyze dilakukan dengan cara studi literatur dan observasi untuk mendapatkan daftar kebutuhan fungsional dan non fungsional. Selanjutnya pada tahapan Design dilakukan perancangan desain user interface, arsitektur dan infrastruktur sehingga menghasilkan prototype aplikasi mobile. Setelah itu pada tahapan Development dikembangkan prototype aplikasi Pada tahun kedua, prototype dikembangkan menjadi aplikasi mobile. Implementasi dilakukan pengisian konten. Konten tidak hanya berupa teks tetapi juga multimedia, virtual reality dan game.
\end{abstract}

Kata kunci: Warisan Budaya, Aplikasi Mobile, Crowdsourcing

\begin{abstract}
Each region has its own cultural characteristics such as traditional houses, language, clothing,etc. Every culture has their philosophy that can be used as role model in life. Therefore, it is so important to documented and spread information of cultural and heritage so young generation have knowledge about their culture. The big challenge are how to collect and store cultural information and also how to present in interested thing so the people interested and easy to learn their culture. Additionaly, Internet penetration and mobile devices are very high in the community. Most people have mobile devices and the internet. The existence of such technology can be utilized to support the documentation and dissemination of Indonesian cultural information. Supporting technologies such as LBS (Location Based Service) can be utilized to determine the location of existing cultural objects. The main challenge in the development of this cultural preservation system is the source and quality of the content. To deal with these challenges, it applied the concept of crowdsourcing to contribute the content. In addition to the wider community, the potential source of cultural content is also from students who develop learning content as a final project / practical work. In this study, we developed mobile applications for preservation of cultural heritage in Indonesia called the application WADAYA. We used ADDIE (Analyze, Design, Developmet, Implementation and Evalution). Analyze phase is done by literature study and observation to get list of functional and non functional requirement. Furthermore, in the design phase design of user interface design, architecture and infrastructure to produce prototype mobile application.
\end{abstract}

Keyword: Mobile Application, Crowdsourcing 


\section{PENDAHULUAN}

Indonesia merupakan negara yang kaya akan warisan budaya dan sejarah alam. Warisan budaya dan sejarah alam terbentuk seiring berjalannya waktu dan sedikit demi sedikit bisa mengalami perubahaan sesuai dengan perkembangan peradaban manusia dan kejadian alam. Kebudayaan itu sendiri merupakan keseluruhan manusia dari kelakuan dan hasil yang harus didapatkannya dengan belajar dan semua itu tersusun dalam kehidupan masyarakat. Kebudayaan memiliki nilai-nilai yang harus dilestarikan. Selain kekayaan warisan budaya yang beragam, sumber dan letak warisan budaya Indonesia juga tersebar di seluruh Indonesia. Salah satu cara untuk melestarikan warisan budaya dan sejarah alam di Indonesia adalah dengan mendokumentasikan dan menyebarkan informasi budaya ini secara luas sehingga tetap dikenal oleh masyarakat Indonesia dan bahkan masyarakat dunia yang ingin mempelajari dan mengenal warisan budaya dan sejarah alam di Indonesia.

Disisi lain, teknologi berkembang dengan pesat. Terbukti dengan munculnya berbagai peralatan elektronik yang bisa digunakan untuk berkomunikasi dan mengakses informasi. Perangkat-perangkat tersebut di antaranya notebook, komputer, telepon seluler, telepon kabel dan lain sebagainya. Masing-masing perangkat tersebut memiliki fitur yang bisa digunakan mengakses aplikasi. Perkembangan teknologi sangat pesat terutama dengan kehadiran Internet. Tercatat saat pada tahun 2012 pengguna internet di Indonesia mencapai 63 juta (APJII, 2013). Penyampaian informasi menjadi lebih mudah, cepat dan kaya konten melalui teknologi website. Website pun berkembang sangat pesat, dari website yang statis sampai dengan dinamis, dari website yang kontributornya hanya dari pengelola website sendiri sampai website dengan konsep CrowdSourcing dimana konten website diberikan oleh pengguna website tersebut. Perkembangan teknologi website juga memberikan dampak tersendiri ke jejaring sosial dimana jumlah pengguna jejaring sosial terus meningkat. Seiring dengan perkembanganan internet, dan perangkat yang bisa dimanfaatkan untuk mendukung akses informasi maka sistem informasi perlu disediakan fasilitas multichannel-acess agar informasi yang ingin disampaikan bisa tersebar secara luas (Aji, Resika Arthana, Yaniar, \& Hasibuan, 2011). Salah satu perangkat tersebut adalah telepon seluler. Penggunaan telepon seluler tradisional hanya berfungsi untuk menelpon dan mengirim pesan singkat berupa SMS, namun telepon seluler saat ini sudah bisa mengakses data internet. Selain itu teknologi pada telepon seluler juga bertambah seperti teknologi LBS dengan bantuan GPS, Compas, Accelometer dan lain sebagainya.

Penelitian pengembangan sistem preservasi warisan budaya dan sejarah alam pernah dilakukan oleh Laboratorium Digital Library and Distance Learning(DL2) Fakultas IImu Komputer (Fasilkom) Universitas Indonesia. Pada penelitian tersebut, dikembangkan produk website untuk mendokumentasikan warisan budaya dan sejarah alam yang ada di Indonesia yang disebut dengan E-Cultural Heritage and Natural History of Indonesia (ECHNH) (DL2 Fasilkom UI, 2016). Sistem yang sudah dikembangkan berbasis website. Pada penelitian ini akan dkembangkan aplikasi mobile Wadaya yang mempermudah masyarakat untuk mencari dan menginformasikan warisan budaya yang diketahuinya.

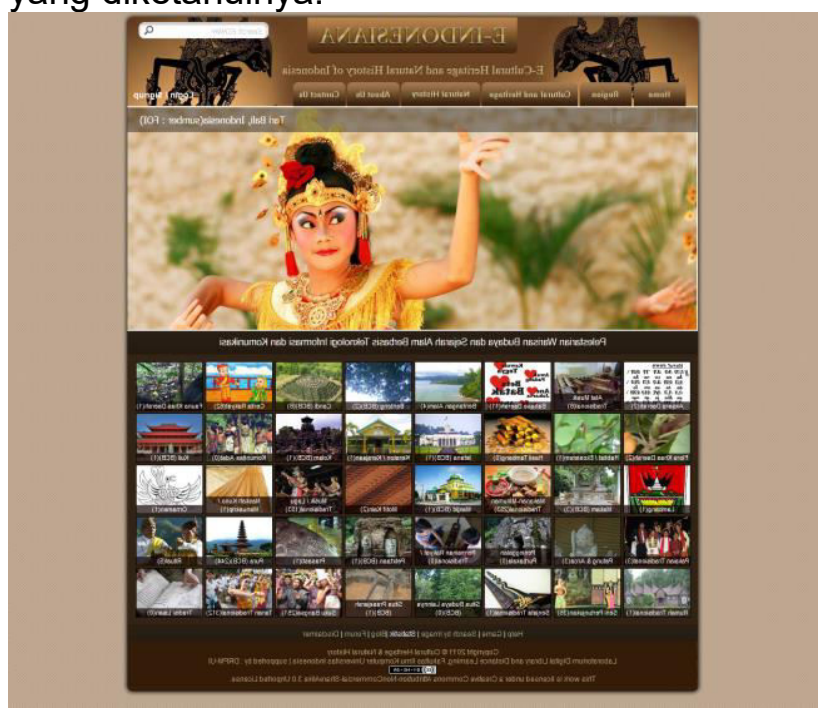

Gambar 1. ECHNH Fasilkom UI (DL2 Fasilkom UI, 2016) 


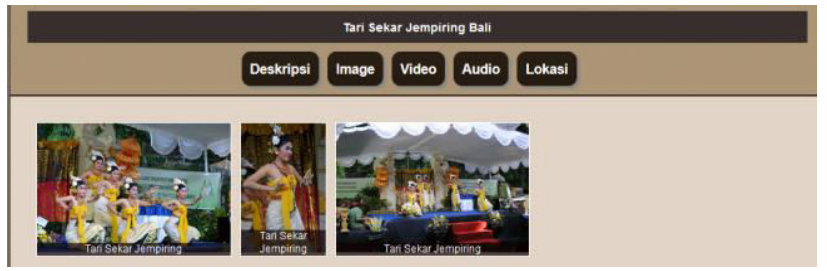

Gambar 2. Contoh salah satu konten ECHNH (DL2 Fasilkom UI, 2016)

\section{Dengan}

memanfaatkan perkembangan teknologi mobile dan semakin banyaknya masyarakat yang menggunakan telepon seluler maka sistem informasi yang dibangun dilengkapi dengan aplikasi mobile untuk memudahkan masyarakat pemberian dan pencarian informasi. Aplikasi mobile akan digunakan oleh masyarakat untuk memberikan informasi objek budaya dan memberikan keterangan tambahan informasi pada objek budaya yang sudah ada. Selain itu pada aplikasi mobile, masyarakat juga bisa mencari objek budaya baik berdasarkan jenis, nama maupun lokasi terdekat dengan posisi saat ini berada. Aplikasi mobile dilengkapi dengan fasilitas geotagging sesuai dengan koordinat posisi yang dideteksi oleh GPS pada telepon seluler untuk memperoleh peta lokasi. Aplikasi yang berjalan pada telepon seluler tersebut akan mengirim data objek budaya ke server. Pada sisi server data objek budaya disimpan dalam basis data dan ditampilkan ke portal website. Agar informasi pada website tersebut bisa tersebar dengan luas, maka website tersebut diintegrasikan dengan jejaring sosial..

Hasil penelitian ini yang merupakan aplikasi mobile Wadaya diharapkan bermanfaat dalam melestarikan warisan budaya yang ada di Indonesia. Selain itu, aplikasi wadaya sebagai wadah bagi penelitian-penelitian terkait untuk mengumpulkan hasil produk penelitiannya. Salah satunya adalah hasil-hasil penelitian produk digital budaya yang dihasilkan dari skripsi mahasiswa. Saat ini, hasil penelitian tersebut masih tersebar dan belum ada wadah khusus sebagai konten warisan budaya.

\section{Studi Literatur}

Pelestarian warisan budaya indonesia menjadi isu yang sangat penting karena letaknya yang tersebar dan kendala yang dihadapi saat pengumpulan data. Pada penelitian IDENTIFIKASI PERMASALAHAN PENCATATAN WARISAN BUDAYA TAKBENDA INDONESIA diungkapkan permasalahan pencatatan warisan budaya terutama yang bukan benda meliputi 1) kesulitan menggali sejarah karya budaya, 2) maestro yang sedikit, 3) sumber tertulis yang terbatas, 4) pementasan karya budaya 5) kondisi geografis, 6) keterbatasan transportasi dan 7) keamanan daerah persebaran karya budaya (Armini, 2014).

Laboratorium Digital Library and Distance Learning Fakultas IImu Komputer Universitas Indonesia melakukan penelitian untuk preservasi warisan budaya dan sejarah alam yang ada di Indonesia. Penelitian ini disebut dengan E-Cultural Heritage and Natural History of Indonesia $(\mathrm{ECHNH})$. Arsitektur $\mathrm{ECHNH}$ didukung oleh berbagai disiplin ilmu pada bidang ilmu komputer Gambar 3

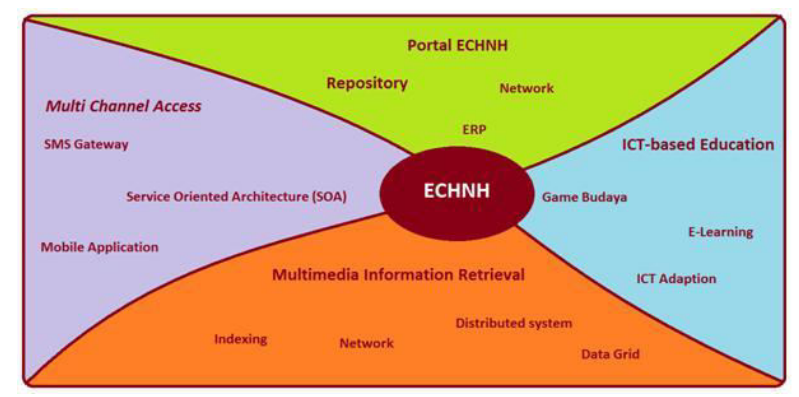

Gambar 3. Arsitektur ECHNH (Hasibuan,

K.Isal, Anggun Baginda, Ahmad, \& Selviandro, 2011)

Beberapa penelitian terkait ECHNH ini seperti pengembangan konten budaya berbasis game (Hasibuan, K.Isal, Anggun Baginda, Ahmad, \& Selviandro, 2011) dan perluasan akses melalui multichannel access (Aji, Resika Arthana, Yaniar, \& Hasibuan, 2011). Pada penelitian ini konten dibagi atas dua jenis yaitu Cultural Heritage dan Natural History. Cultural Heritage terdiri dari :

1) Aksara Daerah

2) Alat Musik Tradisional

3) Bahasa Daerah

4) Bentangan Alam Jurnal Sains dan Teknologi | 61 
5) Benteng (BCB)

6) Candi (BCB)

7) Cerita Rakyat

8) Fauna Khas Daerah

9) Flora Khas Daerah

10) Habitat / Ekosistem

11) Hasil Tambang

12) Istana

13) Keraton / Kerajaan

14) Kolam

15) Komunitas Adat

16) Kuil

17) Lambang

18) Makam (BCB)

19) Makanan-Minuman Tradisional

20) Masjid (BCB)

21) Motif Kain

22) Musik / Lagu Tradisional

23) Naskah Kuno / Manuskrip

24) Ornamen

25) Pakaian Tradisional

26) Patung \& Arca

27) Peninggalan Purbakala

28) Permainan Rakyat / Tradisional

29) Petirtaan (BCB)

30) Prasasti

31) Pura (BCB)

32) Ritual

33) Rumah Tradisional

34) Seni Pertunjukan

35) Senjata Tradisional

36) Situs Budaya Lainnya (BCB)

37) Situs Prasejarah (BCB)

38) Suku Bangsa

39) Tarian Tradisional

40) Tradisi Lisan

\section{HASIL DAN PEMBAHASAN}

\section{A. Analyze}

Pada tahap ini dilakukan analisis kebutuhan sistem secara fungsional dan non fungsional. Penyusunan kebutuhan fungsional dilakukan berdasarkan hasil studi literatur dan observasi terhadap kebutuhan pengguna. Berikut daftar kebutuhan fungsional yang digambarkan dalam bentuk Use Case Diagram.
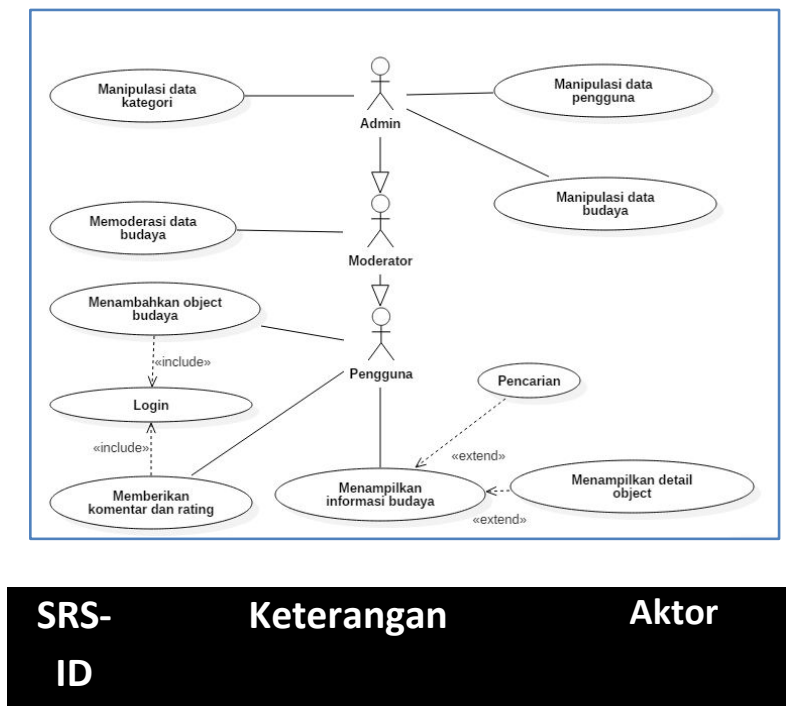

\begin{tabular}{|c|c|c|}
\hline $\begin{array}{l}\text { SRS- } \\
\text { F01 }\end{array}$ & $\begin{array}{l}\text { Manipulasi data } \\
\text { kategori }\end{array}$ & Admin \\
\hline $\begin{array}{l}\text { SRS- } \\
\text { F02 }\end{array}$ & $\begin{array}{l}\text { Manipulasi data } \\
\text { pengguna }\end{array}$ & Admin \\
\hline $\begin{array}{l}\text { SRS- } \\
\text { F03 }\end{array}$ & $\begin{array}{l}\text { Memoderasi data } \\
\text { budaya }\end{array}$ & Moderator \\
\hline $\begin{array}{l}\text { SRS- } \\
\text { F04 }\end{array}$ & $\begin{array}{l}\text { Menambahkan object } \\
\text { budaya }\end{array}$ & Pengguna \\
\hline $\begin{array}{l}\text { SRS- } \\
05\end{array}$ & $\begin{array}{l}\text { Memberikan } \\
\text { komentar dan rating }\end{array}$ & Pengguna \\
\hline $\begin{array}{l}\text { SRS- } \\
\text { F06 }\end{array}$ & $\begin{array}{l}\text { Menampilkan } \\
\text { informasi budaya }\end{array}$ & Pengguna \\
\hline $\begin{array}{l}\text { SRS- } \\
\text { F07 }\end{array}$ & $\begin{array}{l}\text { Menampilkan detail } \\
\text { object }\end{array}$ & Pengguna \\
\hline $\begin{array}{l}\text { SRS- } \\
\text { F08 }\end{array}$ & Pencarian & Pengguna \\
\hline
\end{tabular}

\begin{tabular}{|l|l|}
\hline SKPL-Id & Keterangan \\
\hline SRS-NF01 & Availability - \\
& $\begin{array}{l}\text { Ketersediaan Aplikasi } \\
\text { untuk dapat diakses oleh } \\
\text { pengguna. } \\
\text { Penyedia layanan } \\
\text { aplikasi harus hidup } \\
\text { selama 24 jam. Untuk itu } \\
\text { disediakan server yang } \\
\text { terus online yang bisa } \\
\text { melayani selama 24 jam }\end{array}$ \\
\hline SRS & $\begin{array}{l}\text { Reliability - Kehandalan } \\
\text { Aplikasi, termasuk aspek } \\
\text { NF02 }\end{array}$ \\
& $\begin{array}{l}\text { teknis seperti koneksi, } \\
\text { kebutuhan hardware. }\end{array}$ \\
\hline
\end{tabular}

Jurnal Sains dan Teknologi | 62 


\begin{tabular}{|c|c|}
\hline SKPL-Id & Keterangan \\
\hline & $\begin{array}{l}\text { Hardware } \\
\text { dibutuhkan harus handal } \\
\text { dan bisa menangani } \\
\text { request banyak serta } \\
\text { menyimpan data yang } \\
\text { besar. Pada aplikasi } \\
\text { memerlukan koneksi } \\
\text { internet(download) yang } \\
\text { memadai dan pada sisi } \\
\text { server memerlukan } \\
\text { koneksi internet(upload) } \\
\text { yang bisa melayani } \\
\text { request aplikasi. }\end{array}$ \\
\hline $\begin{array}{l}\text { SRS } \\
\text { NF02 }\end{array}$ & $\begin{array}{l}\text { Portability } \\
\text { Keberpindahan Aplikasi, } \\
\text { sehingga dapat diakses } \\
\text { oleh berbagai device. } \\
\text { Aplikasi web dibuat } \\
\text { Responsive yaitu bisa } \\
\text { dibuka melalui browser } \\
\text { mobile dan komputer. } \\
\text { Layar Aplikasi mobile } \\
\text { mendukung layar } \\
\text { perangkat mobile secara } \\
\text { umum }\end{array}$ \\
\hline $\begin{array}{l}\text { SRS } \\
\text { NF03 }\end{array}$ & $\begin{array}{l}\text { Security }- \text { Keamanan } \\
\text { aplikasi untuk melindungi } \\
\text { data di dalamnya. } \\
\text { Password pengguna } \\
\text { dalam kondisi terenkripsi } \\
\text { tersimpan dalam } \\
\text { database. } \\
\text { Akses terhadap data vital } \\
\text { menggunakan protokol } \\
\text { HTTPS }\end{array}$ \\
\hline
\end{tabular}

\section{B. Design}

Pada tahap ini, dirancang desain antar muka aplikasi Wadaya. Rancangan dikembangkan dengan Balsamiq Mockup.
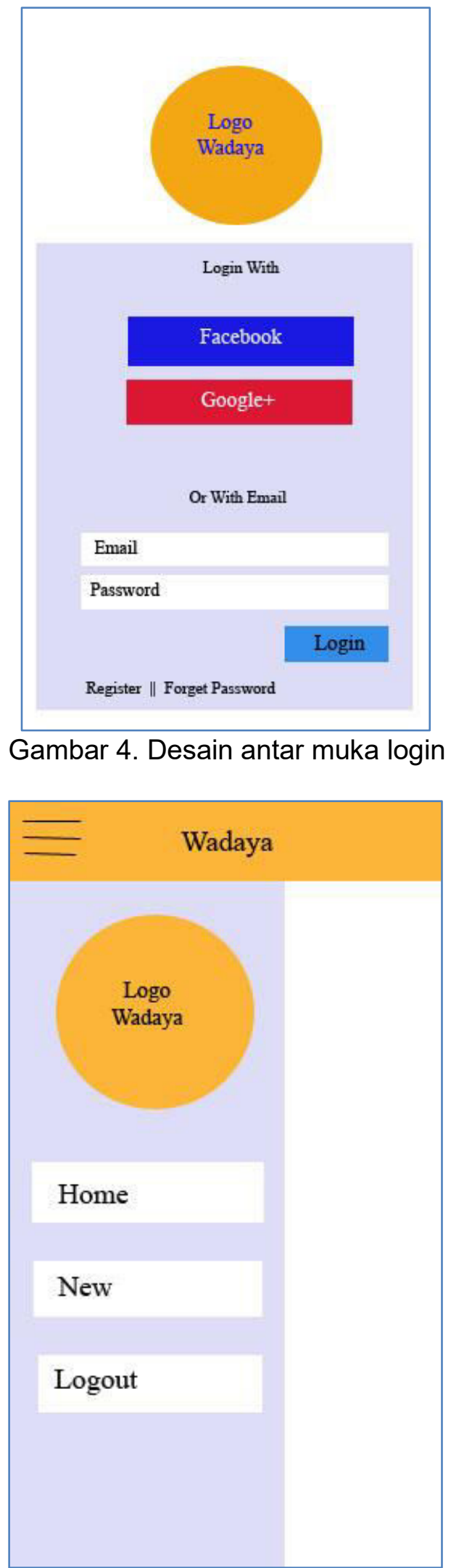

Gambar 5. Desain antar muka menu utama 


\begin{tabular}{|l|}
\hline search \\
\hline Rumah Adat \\
\hline Pakaian Adat \\
\hline Tarian Adat \\
\hline Senjata Daerah \\
\hline Alat Musik \\
\hline Makanan Khas \\
\hline
\end{tabular}

Gambar 6. Desain antar jenis object Budaya

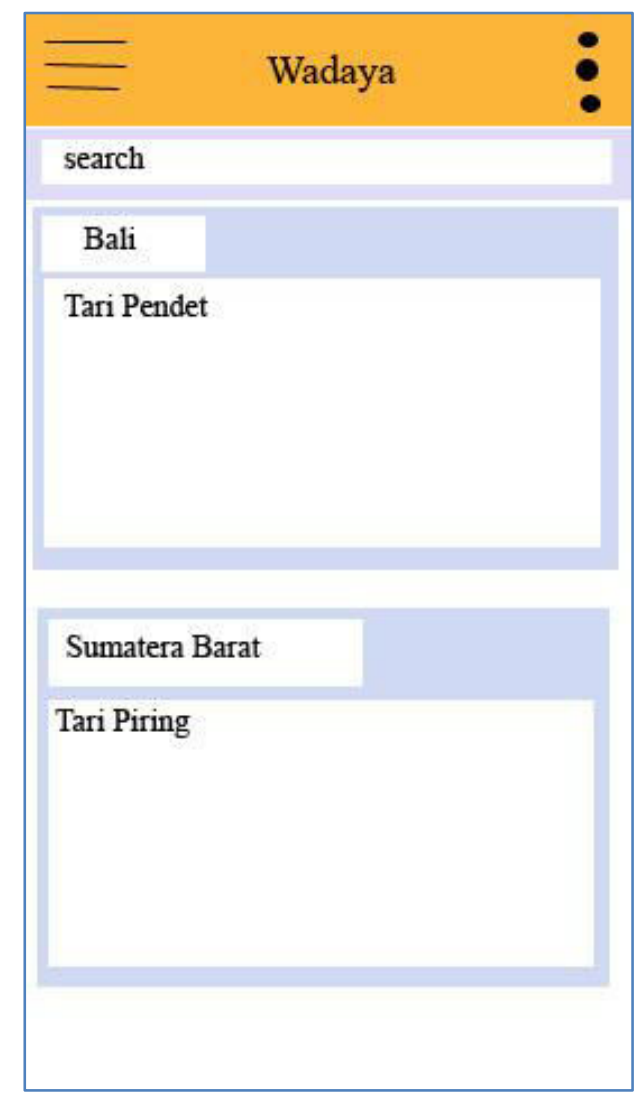

Gambar 7. Berdasarkan wilayah

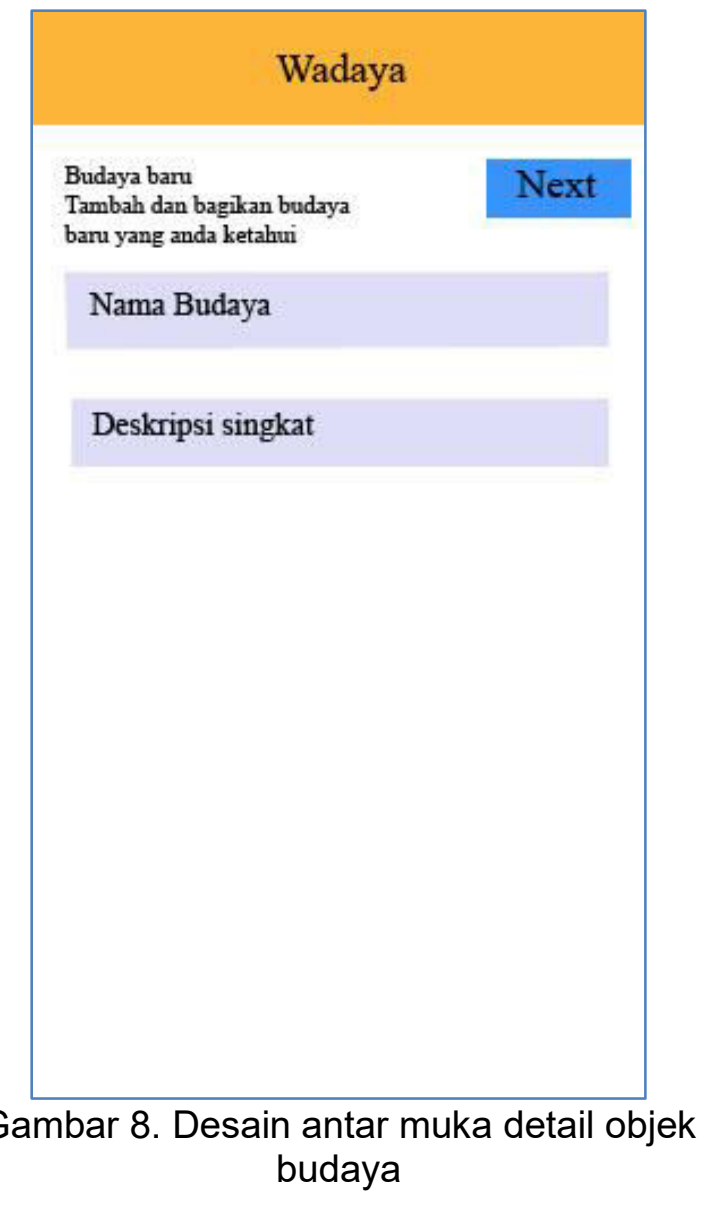

Aplikasi Wadaya terdiri dari aplikasi mobile yang diakses melalui sisi client. Aplikasi ini terhubung dengan

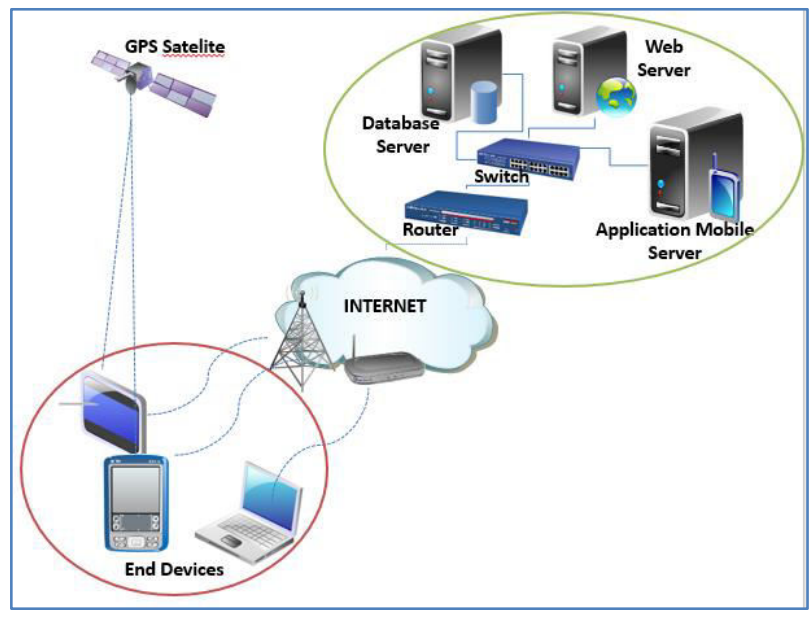

Gambar 9. Arsitektur Infrastruktur Aplikasi 


\section{Development Prototype}

Pengembangan dilakukan dengan menggunakan React-Native, basis data MySQL dan PHP sebagai service Rest-API,

A. Implementasi Halaman Login

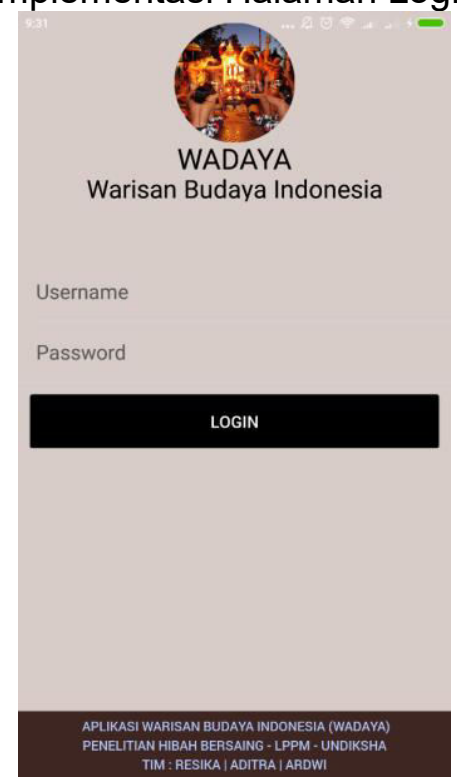

Gambar 10. Implementasi Halaman Login

B. Implementasi Menu Utama

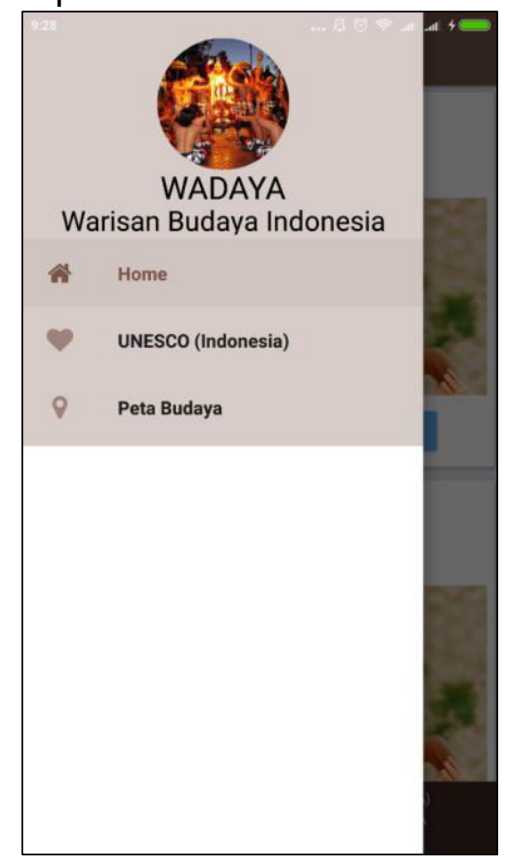

Gambar 11. Implemetasi Halaman Utama

Implementasi Halaman Kategori

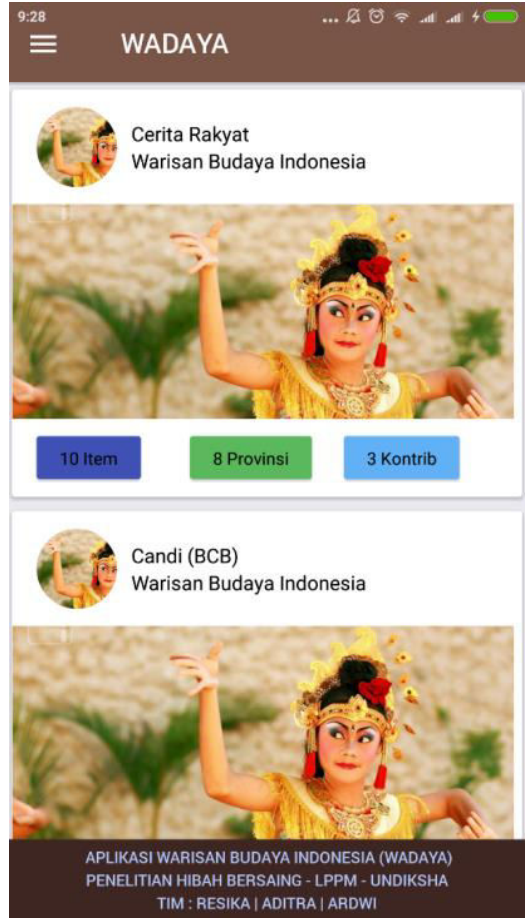

Gambar 12. Implementasi Halaman Kategori

C. Implementasi Informasi Unesco
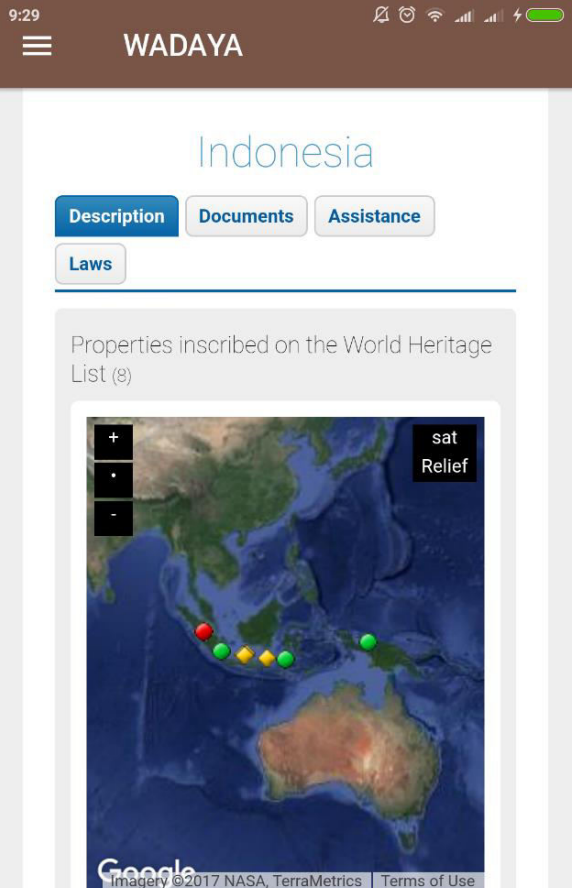

Griatêf

APLIKASI WARISAN BUDAYA INDONESIA (WADAY

PENELITIAN HIBAH BERSAING - LPPM - UNDIKSHA TIM : RESIKA | ADITRA | ARDWI

Gambar 13. Informasi Unesco 


\section{KESIMPULAN}

Pada penelitian ini telah dikembangkan prototype Aplikasi Warisan Budaya (WADAYA) Indonesia. Aplikasi Wadaya merupakan aplikasi untuk menyimpan dan menyebarkan informasi warisan budaya yang ada di Indonesia. Aplikasi wadaya mengadopsi konsep crowdsourcing, dimana informasi warisan budaya berasal dari masyarakat umum. Tahapan pada penelitian ini menggunakan ADDIE. Pada tahap analisis dilakukan analisa kebutuhan sistem secara fungsional dan non fungsional. Kemudian kebutuhan fungsional tersebut diimplementasikan dalam bentuk rancangan antar muka (User Interface) dan arsitektur infrastrutktur. Setelah itu, rancangan tersebut dikembangkan dengan framework ReactNative dan bahasa pemrograman ES6, Database MYSQL dan PHP sebagai service provider. Pada tahapan ini sudah terselesaikan bagian Login, Menu Utama, Halaman Kategori, Halaman Unesco dan pengumpulan data

\section{UCAPAN TERIMAKASIH}

Terima Kasih di ucapkan kepada DRPM Dikti atas pembiayaan yang diberikan terhadap penelitian ini.

\section{DAFTAR PUSTAKA}

Adil, R. (2009). Identifikasi Sinyal Jantung Koroner Dan Perancangan Sistem Monitoring Rekam Medis Online. Jurnal Telkomnika.

Adil, R. (2011). Alat Bantu Monitoring Rate Jantung, Suhu Tubuh dan Kontrol Tetesan Infus Pada Ruang Perawatan Rumah Sakit. The 13th Industrial Electronics Seminar 2011 (IES 2011) . Electronic Engineering Polytechnic Institute of Surabaya (EEPIS).

Aji, R. F., Resika Arthana, I. K., Yaniar, H., \& Hasibuan, Z. A. (2011). Architecture Multichannel-Access of Information Retrieval System Case Study: Indonesian E-Cultural Heritage and Natural History Portal.
International Conference ICCEA'11. China.

APJII. (2013). Statistik Pengguna Internet Indonesia. Retrieved Juni 3, 2013, from Asosiasi Penyelenggara Jasa Internet Indonesi: http://www.apjii.or.id/v2/index.php/re ad/page/halamandata/9/statistik.html

Armini, I. (2014). Identifikasi permasalahan pencatatan warisan budaya takbenda indonesia. Walasuji Volume 5, No. 2,, 197-208.

Atkielski, A. (2007). Electrocardiography. Retrieved from Wikipedia: https://en.wikipedia.org/wiki/Electroc ardiography\#/media/File:SinusRhyth mLabels.svg

DL2 Fasilkom UI. (2016). E-Cultural Heritage and Natural History of Indonesia. Retrieved from E-Cultural Heritage and Natural History of Indonesia: http://eindonesiana.cs.ui.ac.id/echnh-ng

Hasibuan, Z. A., K.Isal, Y., Anggun Baginda, N., Ahmad, M., \& Selviandro, N. (2011). Preservation of Cultural Heritage and Natural History through Game Based Learning. International Journal of Machine Learning and Computing, Vol. 1, No. 5, December 2011 (pp. 460-465). Chengdu: IJMLC.

N.S.A.Zulkifli, F.K.Che Harun, \& N.S. Azahar. (2015). XBee Wireless Sensor Networks for Heart Rate Monitoring in Sport Training. IEEE.

Philip Tobianto Daely. (2015). PEMANTAU SINYAL VITAL PASIEN NIRKABEL MENGGUNAKAN PROTOKOL ZIGBEE PADA PLATFORM EHEALTH. Universitas Telkom, S1 Teknik Elektro 2015.

WHO. (2016). World Health Organization. Retrieved from E-Health: http://www.who.int/trade/glossary/st ory021/en/ 